\title{
Responsible Leadership in a Stakeholder Society - A Relational Perspective
}

\author{
Thomas Maak \\ Nicola M. Pless
}

\begin{abstract}
We understand responsible leadership as a social-relational and ethical phenomenon, which occurs in social processes of interaction. While the prevailing leadership literature has for the most part focussed on the relationship between leaders and followers in the organization and defined followers as subordinates, we show in this article that leadership takes place in interaction with a multitude of followers as stakeholders inside and outside the corporation. Using an ethical lens, we discuss leadership responsibilities in a stakeholder society, thereby following Bass and Steidelmeier's suggestion to discuss "leadership in the context of contemporary stakeholder theory" (1999: 200). Moreover, from a relational and stakeholder perspective we approach the questions: What is responsible leadership? What makes a responsible leader? What qualities are needed? Finally, we propose a so-called "roles model" of responsible leadership, which gives a gestalt to a responsible leader and describes the different roles he or she takes in leading stakeholders and business in society.
\end{abstract}

Dr. Thomas Maak is a Research Director at the Institute for Business Ethics and Reader in Corporate Responsibility at the University of St. Gallen (Switzerland). He earned his Ph.D. in Business Ethics, Summa Cum Laude, from the University of St. Gallen and held visiting appointments at Columbia University and Georgetown University. Currently, he is a member of the executive committee of the European Business Ethics Network EBEN.

Dr. Nicola Pless is a former Vice President of leadership development at a large financial services institution. Currently she is a Research Director at the Center for Public Leadership and Reader in Responsible Leadership at the University of St. Gallen. She holds a Ph.D. in organizational theory and social issues from the University of St. Gallen and a diploma in clinical organizational psychology from INSEAD.

Both the authors are Visiting Senior Research Fellows at INSEAD, France, where they co-direct a research stream on "Developing responsible leadership for sustainable business" within the PwC-INSEAD initiative on high-performing organizations. They are the editors of "Responsible Leadership", published by Routledge in 2006.
KEY WORDS: responsible leadership, leadership, stakeholder theory, leadership roles, relational intelligence

\section{Leading in a global and interconnected world}

Today's leaders act in a global, complex, uncertain and interconnected business environment. Among the challenges in this context is the need to reduce complexity and uncertainty for people and provide a desirable picture of the future, which is shared by the people they lead. Leaders need to have a sense of purpose and a guiding vision, which help bundle individual and "organizational energy" (Cole et al., 2005) and navigate the firm through uneven and sometimes murky waters. Moreover, they have to lead in a business environment, which undergoes a general crisis of legitimacy (Wheeler and Silanpää, 1997) and trust, which has been lost over the years of environmental disasters (e.g. Shell Nigeria, Bhopal), accounting scandals (e.g. Enron, Worldcom, Parmalat), and ethical misconduct in various shapes and forms (e.g. Nike, Martha Stewart). In a global stakeholder society, "where companies are expected to be accountable not only to shareholders for financial performance, but to stakeholders for their wider economic, environmental and societal impacts" (Wade, 2006: 227), commercial viability and long-term business success depend on the ability of a firm and their leadership to act responsibly with respect to all stakeholders in business, society and the environment (Freeman, 1984, 1994, 2005; Donaldson and Preston, 1995; Wheeler and Sillanpää, 1997; Svendsen, 1998; Phillips, 2003, Maak and Pless, 2006). An important part of the effort to create sustainable business success is the leadership responsibility to (re)build public trust (DiPiazza and 
Eccles, 2002), to regain the license to operate from society and to earn and sustain an impeccable reputation as a "great company" (Collins, 2001) and corporate citizen, which can only be achieved by walking the talk, managing with integrity, making "profits with principles" (Roddick, 1991), delivering on the "triple-bottom-line" (Elkington, 1998) and "creating value for stakeholders" (Freeman, 2004: 365).

Such a context also affects (or, should affect) the mindset, the roles and responsibilities of leaders, which simultaneously change, become more complex and multi-faceted, expand from an internal leadership perspective to a broader world view, from a shareholder mindset to a stakeholder orientation with respect to the leadership mandate. Yet, in an interdependent and turbulent world this cannot be achieved in isolation by the "great man" alone or the charismatic leader. In other words, "we don't need another hero" (Badarracco, 2001). Rather, winning the mandate to lead requires a relational leadership approach based on inclusion, collaboration and co-operation with different stakeholder groups (Wicks et al., 1994). In a stakeholder society, leadership has to reach beyond traditional leaderfollower concepts. Here, the leader becomes a co-ordinator and a cultivator of relationships towards different stakeholder groups. In the following, we will give an exemplary overview of some leadership responsibilities with respect to some key stakeholders.

\section{Employees}

Responsible leaders mobilize people and lead teams, often across business, countries and/or cultures to achieve performance objectives that are derived from the strategic objectives of the firm. They also coach and reinforce employees to achieve these objectives in an ethical, respectful and "relationally intelligent" way (Pless and Maak, 2005). They create incentives to encourage respectful collaboration inside and outside the organization, to foster responsiveness to stakeholders (Freeman, 2004) and advocate ethical behaviour. They safeguard freedom of speech and support the voicing of ethical wrongdoing. They ensure that employment standards are adhered to (worldwide, and also in the supply chain); that working conditions are humane, safe, healthy and non-discriminatory; that employees regardless of background (nationality, gender, age, etc.) are provided fair and equal employment opportunities and that the needs of employees for recreation, work-life balance and meaningful work are addressed. At The Body Shop, e.g. CEO Paul Saunders "has ultimate responsibility for the safety, health and well-being of employees. He also has a moral obligation to ensure that fair and decent labour practices are upheld in our franchisee and supply chain networks" (The Body Shop, 2004: 6).

\section{Clients and customers}

Responsible leaders make sure that the products and services meet the needs of their customers and clients, that they are safe and not harmful (such as asbestos) and that real and potential risks are openly and transparently communicated. A leader also takes preventive steps in order to ensure customers' wellbeing, as e.g. the former CEO of Johnson\&Johnson, James Burke, did in the now classic Tylenol case. After poisoned Tylenol bottles were discovered in the Chicago area, Burke gave immediate orders to pull all Tylenol products from the shelves in North America, not knowing if the incident was more than a local happening. For Burke, however, as for J\&J, the well-being of patients and safety of customers had priority and could under no (business) circumstances be compromised.

\section{Business partners}

Responsible leaders ensure that ethical, environmental and labour standards are also respected and applied by their business partners. Furthermore, they make sure that the business partners themselves are treated respectfully and fairly (e.g. no preferential treatment) by company's employees and managers. Ultimately, it is in the discretion of leadership with whom to do business. Anita Roddick, founder of The Body Shop, decided for instance to source some product ingredients from underprivileged communities in developing countries and thereby initiated the company's "Trade Not Aid" programme, building sustainable relations to these 
communities. The programme ensures fair prices and trading conditions and aims at supporting the communities to become self-sustainable and improving their standard of living (Roddick, 1991).

\section{Social and natural environment}

In a "stakeholder corporation" (Wheeler and Sillanpää, 1997), leaders need to be sensitive to the world in which they operate. They assess the impact of business decisions on the social and natural environment. They engage stakeholders in an active dialogue, include different voices, take their interests and needs seriously and assess them in a thorough reflection process. They also make sure that production processes are as environmentally friendly as possible by using "green" technology and renewable resources, by recycling material, by saving energy etc. Furthermore, they foster contributions to society. Apart from passive actions like charity and corporate giving, they encourage active engagement for the well-being of communities, e.g. by setting up foundations and providing volunteering opportunities for all employees. They also coach and train their people in sustainable development (Wade, 2006) and help them develop a broader understanding of the responsibilities of business in society and support them in growing competencies in building sustainable stakeholder relations. PricewaterhouseCoopers' Ulysses programme is an example how this can be achieved, namely by sending up-coming global leaders into developing countries to work with different stakeholders (e.g. local social entrepreneurs, government agencies and international organizations) on aid projects that have an immediate and sustainable benefit for the communities (see Pless and Schneider, 2006).

\section{Shareholders}

Responsible leaders safeguard shareholders' investment capital and ensure an adequate return. They respect their rights and also ensure regular communication and transparent reporting on the economic, social and ecological performance of the corporation. They are steadfast and do not compromise one performance objective for another, even when set under pressure. Furthermore, they show due diligence with respect to their own and others' insider knowledge and proactively prevent any moral wrong-doing (e.g. insider trading). They also act responsibly and modest with respect to their own compensation packages. In fact, they need to be able to balance short-term profit and return expectations and the long-term sustainability of the business. Ultimately, they consider the interests of shareholders as one set of potentially legitimate interests among others.

This brief overview has shown that leadership in a global and interconnected world occurs in interaction with a multitude of stakeholders - locally and globally, inside and outside the corporation. In fact, the interaction of leaders with a diversity of stakeholder groups confronts them with a number of demanding challenges: "an ethics challenge (how to recognize, assess and deal with a multitude of stakeholder interests, based on different world views and values, how to cope with ethical dilemmas, etc.), a diversity challenge (how to lead diverse people across distance, businesses, countries and cultures; how to create a multicultural (Cox, 2001) and inclusive (Gilbert and Ivancevich, 2000; Pless and Maak, 2004) environment, in which people find meaning, feel valued and respected and can contribute to their highest potential), a business in society challenge (how to earn the licence to operate; how to make the business case for responsibility; how to become a good corporate citizen) and, finally, a stakeholder challenge (how to create sustainable and trustful relationships with different stakeholders; and how to rebuild trust in a business world that has been shattered by corporate scandals)" (Pless and Maak, 2005).

Against this background we contend first that leadership takes place in relationships - they "are the centre of leadership" (Maak and Pless, 2006: 39); second that leadership is rooted in values and norms and that ethics is "at the heart of leadership" (Ciulla, 1998, 2006); and third that the building and cultivating of ethically sound relations towards different stakeholders is an important responsibility of leaders in an interconnected stakeholder society. We thus follow the suggestion of Bass and Steidlmeier and discuss "leadership in the context of contemporary stakeholder theory" (1999: 200), especially with regard to the work of Ed Freeman and collaborators, thereby using an ethical lens. 


\section{Leadership and stakeholder theory}

The first systematic discussion of stakeholder theory goes back to Freeman's book "Strategic management: a stakeholder approach", which was published in 1984. Over the course of the past 20 years stakeholder theory has developed significantly: The functional understanding of stakeholders as being a means to corporate ends has evolved to a moral understanding of stakeholders as being ends in themselves - individuals/groups with own interests that the firm was constructed to serve (Freeman and Gilbert, 1989). The research perspective on stakeholder theory has broadened from a descriptive and instrumental perspective to a normative viewpoint (Donaldson and Preston, 1995). The underlying individualistic and masculine assumptions have been unveiled with the consequence that the stakeholder concept has been re-interpreted from a feminist perspective, putting emphasis on the structure of relationships (Wicks et al., 1994) and the quality of interactions (Freeman, 2004). Instrumental, theoretical constructs such as agency theory, transaction cost and contract theory have been replaced by ethical ways of explaining stakeholder relations (Freeman, 2004).

According to Freeman et al. (2004) stakeholder theory starts with "the assumption that values are necessarily and explicitly a part of doing business. It asks managers to articulate the shared sense of the value they create, and what brings its core stakeholders together. It also pushes managers to be clear about how they want to do business, specifically what kinds of relationships they want and need to create with their stakeholders to deliver on their purpose." (364). Ultimately, stakeholder theory asks two key questions: "What is the purpose of the firm?" and "What responsibility does management have to stakeholders?" (ibid.). In fact, it stresses the importance of considering the "legitimate interests of those groups and individuals who can affect (or be affected by)" (Freeman et al., 2004: 365) the activities of the corporation and "emphasizes the importance of investing in the relationships with those who have a stake in the firm" (Freeman, 2004: 234).

Against this background, we will discuss in the following the meaning of responsible leadership. First, the concept of responsible leadership suggests not to look at leadership from a descriptive and instrumental perspective as traditional leadership theory does, but from a normative point of view. Instead of understanding leadership as being valuesfree we understand it as a moral, values-based and thus normative phenomenon. Second, it implies to understand leadership as a social-relational phenomenon (Smircich and Morgan, 1982; Berger and Luckmann, 1966) that occurs in interaction with different groups of followers. As a consequence, the focus of the leader-follower relationship is broadened: instead of focusing solely on the leader-subordinate relationship in the organization we consider a wider range of relevant stakeholders as followers, inside and outside the organization (i.e., peers, clients and NGOs). Third, it suggests to look into the quality of interactions and to ask, "How are the objectives achieved?"

Moreover, placing leadership in the context of stakeholder theory triggers new questions with regard to leadership: What is the purpose of leadership in a stakeholder society? What responsibilities do leaders have with respect to the firm, to the people/constituents they lead, to society and nature and to themselves? Who are the actors in the leaderfollower relationship? What makes a responsible leader? What are the ethical underpinnings of this relationship? What are the qualities needed? What are the implications for the leader's roles? Conscious of the fact that this can only be the beginning of a larger discussion on the topic, we want to start the dialogue by discussing some of the questions posed.

\section{Towards a theory of responsible leadership}

What is the purpose of leadership in a stakeholder society?

This question is as fundamental as it is a normative one. In mainstream leadership theory, which explains leadership in the context of hierarchically structured firms, driven by profit and shareholder value maximization, the leader as great man is expected to influence "followers to achieve group/ organizational goals that reflect excellence defined as some kind of higher-level effectiveness" (Rost, 1991: 91). From a moral point of view, the political scientist Burns (1978) sees the purpose of leadership and the leader-follower relationships as a 
transforming one, through which " $\ldots$ one or more persons engage with others in such a way that leaders and followers raise one another to higher levels of motivation and morality" (Burns, 1978: 20). While certainly desirable, this claim is rather unspecific and general and does not really help business leaders to understand their leadership purpose. Furthermore, given the diversity of followers that have a stake in the leadership relationship and the often conflicting interests and values among these stakeholders this claim is even more difficult to realize for a business leader.

If we understand the purpose of leadership in the context of stakeholder theory and the corporate responsibility debate, it seems more feasible to link it to both the concept of the "triple-bottom-line" (Elkington, 1998) and the idea of sustainable development at large. Both concepts imply that corporations are no longer solely accessed against their economic bottomline, but also against their ability to preserve and improve the state of the natural environment and to contribute to the wellbeing of society, helping to meet "the needs of the present without compromising the ability of future generations to meet their needs" (Brundtland, 1987: 8). In this context the purpose of leadership can be understood as to build and cultivate sustainable and trustful relationships to different stakeholders inside and outside the organization and to co-ordinate their action to achieve common objectives (e.g. triplebottom-line goals), business sustainability and legitimacy and ultimately to help to realize a good (i.e., ethically sound) and shared business vision.

\section{Who are the actors in the leader-follower relationship?}

Responsible leadership is a relational and ethical phenomenon, which occurs in social processes of interaction with those who affect or are affected by leadership and have a stake in the purpose and vision of the leadership relationship (Freeman et al., 2006). As we argued in the beginning, the context of leadership has changed and with it the responsibilities that leaders have vis-à-vis different stakeholder groups. Broadening the view from a leader-subordinate relationship to a leader-stakeholder relationship challenges some of the underlying assumptions of traditional leadership theory. Mainstream leader- ship theory understands the leader-follower relationship as an unequal relationship with the leader being in charge (Bennis and Nanus, 1985) and followers being dedicated to "do the leader's wishes" (Rost, 1991: 70). This understanding allows us to explain leader-follower relationships in hierarchical and dyadic terms (e.g. leader member exchange theory; Graen and Uhl-Bien, 1995), assuming that leadership authority comes through status and position power. However, it does not help to explain leadership success in vertical network structures where leaders mobilize stakeholders - who are ultimately of equal status and do not directly depend on them - to follow them to collaborate for a common purpose, and to realize a desirable and moral vision without having formal power and authority. Obviously, this adds to the complexity of the leadership project and confronts leaders with numerous relational challenges ranging from dealing with different values sets, mindsets, interaction styles to coping with conflicts of interests, solving multicultural problems and reconciling ethical dilemmas. Further below, we will discuss what qualities leaders need in order to cope with these challenges.

What is the function of the leader in the leader-follower relationship?

The evolution of corporations from hierarchical to network structures, from national to transnational operations, from a shareholder focus to a stakeholder orientation, from an understanding of being independent players in society to becoming corporate citizens, also affects the understanding of what leadership implies and how it can be differentiated from what followers do. In mainstream leadership theory, rooted in hierarchical thinking, leaders are understood as "one person, sitting at the top of a hierarchy, determining for a group of loyal followers, the direction, pace, and outcome of everyone's efforts" (Nicoll, 1986: 30). They are understood as being active (Bass, 1990) while followers are passive; as possessing superior knowledge and expertize, based on which they create order and control and get others as means to implement their goals and interests. Critical leadership theorists point out that this understanding of leadership cannot be distinguished from, but equals management (e.g. Rost, 
1991). In the vertical context of a network organization and a stakeholder environment, however, the task of leadership gets a new meaning. The leader can no longer be seen as the one separated and detached individual at the top of a pyramid (Helgesen, 1990), as the sole creator of reality, as the one who "attempts to construct the social world for others" (Greenfield, 1984: 142, cited in Rost, 1991). In a network context where leadership occurs in interaction with different stakeholders, the leader needs to be part of, and integrated in, the web of stakeholder relationships. Leadership legitimacy does not come with position, status, reward or coercive power. It is only in and through the stakeholder relations that leadership legitimacy can be earned from stakeholders as followers. And it is only in a process of co-creation of all parties involved that commonly shared objectives can be achieved.

In this sense, the results and success of leadership depend on the constructions and co-ordinated actions of both leaders and stakeholders (as followers or co-leaders), not on the individualistic great man. If leadership resides within such relationships (Foster, 1989; Rost, 1991) and if the purpose of leadership is to achieve a commonly desired vision, then the primary focus of the leader needs to be on the relationships with those who have a stake in the leadership project. The leader becomes a cultivator of these relationships in terms of their quality and desired values base and a facilitator of relational processes (we will specify further below what that means for a leader's roles).

As a cultivator and facilitator of relationships leaders care about the needs and interests of others and of the stakeholders involved. They facilitate relational processes to realize the commonly shared vision, such as stakeholder dialogues, mediations of conflicts of interests, negotiations, problem solving and decision making processes, creativity and innovation workshops, reconciliation of dilemmas etc. In these interactive and communicative processes they ensure that people are treated fairly and as equal and vulnerable human beings; that they feel respected and recognized that their voices are heard and understood; that others feel integrated in a process of co-creation, empowered to share their experiences, expertize, resources, creativity and qualities and mobilized to contribute to their highest potential for achieving common objectives, and ultimately, real- izing the commonly shared and desired vision. Against this background, we now turn to the question of what makes a responsible leader.

\section{What makes a responsible leader?}

Responsible leadership is the art of building and sustaining good relationships to all relevant stakeholders (Maak and Pless, 2006: 40). A responsible leader's core task is to weave a web of inclusion where the leader engages himself among equals. Plato already saw this quite clearly in his "Statesman" where he noted that people are not sheep, and leaders are not shepherds; instead Plato regarded the leader as a weaver, whose main task was to weave together different kinds of people into the fabric of society. (Plato, 1971; cit. in Ciulla, 2004: 322). While leaders are accountable for facilitating the relational processes with and among stakeholders as followers, they are also responsible for the quality of these relationships - that they are inclusive and based on ethically sound values that the interaction partners respect and act according to these values and that the leader-followers relationship serves a common and good purpose.

As we discussed in the beginning, leaders have responsibilities vis-à-vis different stakeholders: They need to integrate people from different cultures to work together effectively; they need to care for the well-being of different constituencies (e.g. indigenous people in the countries where the company produces); they need to understand the interests, needs and values of different groups and facilitate dialogue among them; simultaneously, they need to mobilize and align the energy of different people for achieving common objectives and support the realization of a common and good vision. Obviously, this requires "socialized", not "personalized" leaders (Howell and Aviolo, 1992): Leaders, who have the intellectual capacity to cognitively seize, process and assess complex situations, problems and developments from different stakeholder viewpoints and with respect to diverse and sometimes conflicting objectives; who act according to a humane and moral values base, show authenticity and integrity, and care for the needs and interests of others, thereby demonstrating good character; who use relational intelligence (RI) in interacting with different 
stakeholders and apply emotional and ethical intelligence in coping with emerging conflicts of interests, while making far-reaching decisions and reconciling ethical dilemmas. While many leaders have excellent cognitive and intellectual capacities, it is moral character and RI that distinguishes good from great - as responsible leaders.

Indeed, having a good character and being a moral person are at the core of being a responsible leader (Ciulla, 1998; Solomon, 1999; George, 2003). Ethics, as Ciulla (1998) argues, is (at) "the heart of leadership". But what does this imply? Does it mean that a leader, to be considered responsible, has to be a better person? Does leadership ethics require "moral leadership"? Moreover, do we expect from leaders to be moral heroes? Should leaders be held accountable by different moral standards because they hold more responsibility for others? If agreed, this would imply that leaders may consider themselves an exception from the rule. This, however, can turn out to be a two-way street: leaders, instead of being a shining example for good, i.e., moral leadership could engage in narcissistic or even bad leadership behaviour (Maccoby, 2000; Kellerman, 2004), as we witnessed for instance in the case of Enron. Ciulla (2006), therefore, convincingly argues that we should not hold leaders to higher moral standards but to the same standards as the rest of society. Yet, the responsibility of a leader is to safeguard moral values, to promote them in the network of leader-follower relationships and to act upon them in a consistent way. It is important that leaders stay true to desirable moral values and principles no matter how tempting or challenging a situation might be. George (2003: 20) notes that staying true, being authentic, leading with integrity, is only possible if principles and leadership practice match. Thus, practised morality is the showcase for a person's integrity: if followers perceive that a leader's values and principles match his or her actions - and that he or she walks the talk, then they will attribute the leader integrity and, ultimately legitimacy. Trust by stakeholders is what follows.

We thus note that responsible leaders should have character; they should be led by desirable virtues and principles, such as respect, care, honesty, accountability, humility, trust and active citizenship; and they should practise "introspection" (George, 2003).
In the following we will discuss the relational qualities that leaders need to cope responsibly with a diversity of stakeholders as their followers.

\section{What qualities do responsible leaders need?}

Former Medtronic CEO George notes on his time as a leader (2003: 23, 24): "The capacity to develop close and enduring relationships is one mark of a leader. (...) Authentic leaders establish trusting relationships with people throughout the organization as well as in their personal lives. The rewards of these relationships, both tangible and intangible, are long lasting." However, as we have seen above, the importance of establishing trusting relationships extends well beyond the organization and the personal life of a leader. Most of the challenges that leaders face in an interconnected world emerges from the interaction with a multitude of stakeholders, locally, regionally and globally; both inside and outside the organization (Maak and Pless, 2006: 39). They require leaders to integrate people with different styles and cultural background into teams, include different voices into the dialogue, understand issues from different perspectives, solve conflicts of interests with different people, reconcile intercultural and interpersonal dilemmas. Thus, the greater the need to engage with different stakeholders who have different values, interests and needs, the more important it becomes for leaders to be able to connect with them, to understand different perspectives, to balance sometimes conflicting claims and to act both interpersonally and ethically competent. In order to do that, a responsible leader needs both moral and relational qualities.

We have argued elsewhere that leaders need "relational intelligence (RI)" in order to connect and interact effectively and respectfully with people and stakeholders from various backgrounds, diverse cultures and with different interests, inside and outside the organization..." (2005: 2) and to build lasting and trustful relationships. RI is based on a combination of emotional intelligence (Salovey and Mayer, 1990) and "ethical intelligence" (Pless and Maak, 2005). This means that responsible leaders need both, emotional and ethical qualities to guide their action and behaviour in interaction. According to Mayer et al. (2001) emotional intelligence can be 
divided into four areas: perceiving emotions, using emotions to facilitate thought, understanding emotions and managing emotions in a way that enhances personal growth and social relations (2001: 234). Ethical intelligence consists of three key components: moral awareness, moral reflection and moral imagination. Moral awareness is the ability to recognize and understand values, norms and interests in oneself as well as in others and to discriminate among both. Reflection skills and critical thinking enable leaders to take a critical perspective on themselves, and the organization, but also on the claims and interests of others (stakeholders, e.g.). It helps to generate an orienting perspective and enables moral reasoning, both are necessary to make informed, balanced and morally sound decisions. This kind of moral reflection is what makes a reflective practitioner (Schön, 1983). And moral imagination (Johnson, 1993; Ciulla, 1995; Werhane, 1999) helps a leader solve moral dilemmas in new ways without compromising her integrity.

To sum up, while ethical intelligence fosters moral awareness and reflection and provides for imagination and orientation, emotional intelligence supports emotional awareness, reflection and emotional regulation. Both help leaders relate and interact with their stakeholders in an interpersonally and mature way with care, empathy and foresight. Therefore, if responsible leadership is about building trust and cultivating sustainable relationships towards different stakeholders, then leaders need both emotional and ethical qualities (RI) that help them interact responsibly.

\section{Modelling a (responsible) leader's roles}

Leadership is a social and normative phenomenon that occurs in interaction between leaders and their followers. Today, it is embedded in the context of flattened hierarchies and networked structures, of global markets with multicultural workforces and increased corporate influence and power, of a global stakeholder society in which corporations need a license to operate and are expected to act as good corporate citizens. Against his background, as we have argued above, new leadership challenges emerge. These challenges have an explicitly relational character and require from leaders emotional, multicultural, ethical and relational qualities, sum- marized in the notion of RI. A leader in a stakeholder society needs to balance the external pressure of conflicting interests and demands by stakeholders, and the internal tension of being a coherent and consistent person that leads with integrity. To better understand the responsibilities that leaders have with regard to leading stakeholders, to balancing internal and external pressures and to tackling the leadership challenges we introduce a "roles model" of responsible leadership, which helps us approach leadership from a new angle.

Surprisingly, leadership research has not paid much attention to the significance of leadership roles, let alone their ethicality and multiplicity in a stakeholder environment. Rather, it focuses on traits and personality attributes (Bass, 1990; Black et al., 1999), charisma (Conger and Kanungo, 1987), leadership styles (Bass, 1967; Blake and Mouton, 1985; Hersey and Blanchard, 1988), or situational factors (Fiedler, 1967). We find extensive research on both transactional and transformational leadership, as well as leader-member exchange theory (Graen and Uhl-Bien, 1995), all of which focus on exchange processes and questions of utility and effectiveness. If at all, role differences are considered with respect to their functionality as "action logic" (Rooke and Torbert, 2005) and thus their effectiveness in influencing followers to achieve a certain result. Therefore, we have to look into other areas to seek support for the plausibility of a roles model. Merton's role theory (1957) is a good starting point to do this. Merton contends from a sociological perspective that social status involves an array of associated roles that is a role set as "complement of role-relationships on which persons are involved by virtue of occupying a particular social status (...) relating the status-occupant to diverse others" (110111). He adds a distinctive feature of a role set, namely its structural significance - it is concerned with arrangements integrating diverse roles into one role set, as opposed to the question of how individuals deal with multiple roles resulting from the relations in which they find themselves (e.g. father, friend and manager). We can connect the concept of an integrated role set to our purpose of defining a "roles model" of responsible leadership: the various roles which will be outlined below are part of an integrated whole. They are neither isolated from each other, nor do they reflect a different action logic. 
Mintzberg (1975) argued in a similar way in his seminal piece on "The manager's job" in which he introduces 10 managerial roles, organized in interpersonal, informational and decisional roles: "In the terminology of the psychologist, they form a gestalt, an integrated whole. No role can be pulled out of the framework and the job be left intact." (59)

Therefore, the roles, to which we now turn, do not reflect different persons, but one integrative being - the leader. As Figure 1 shows, leaders are embedded in a network of stakeholder relations (direct reports, customers, suppliers, peers, family, community etc.). To foster collaboration and to mobilize and align these stakeholders (with different backgrounds, values and sometimes conflicting interests) with respect to a commonly shared vision, leaders need to exercise certain roles: being a steward and as such a custodian of values and resources; a good citizen and thus an active and caring member of communities; a servant to others; as well as a visionary by providing inspiration and perspective with respect to a desirable future. Having strong normative connotations, the roles in the inner circle are key to the self-image and self-understanding of a responsible leader and will thus be discussed in more detail.

Connected to these roles are the more "operational" ones of being the architect of inclusive systems, processes and a moral infrastructure; change agent and transforming leader; coach by supporting followers; and storyteller and meaning enabler, that is the creator and communicator of moral experience and enabler of shared systems of meaning. It should be emphasized again that all these roles are relational, that is, they concern specific responsibilities or activities vis-à-vis relational processes in the construction of organizational realities (Dachler, 1992). As such, they showcase responsible leadership and even if their meaning and temporal significance

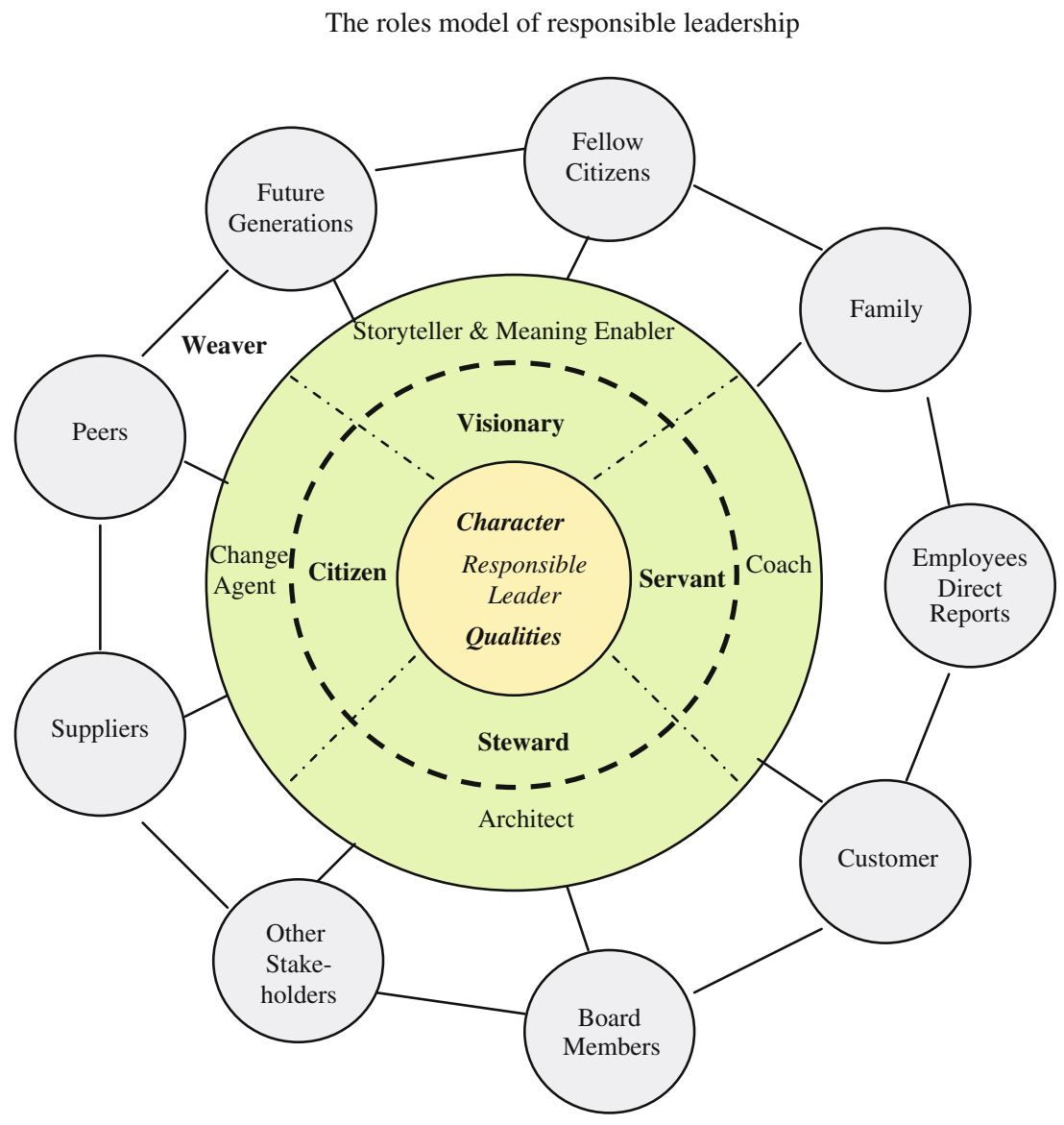

Figure 1. The roles model of responsible leadership. 
differs, they belong to each other since a proper "gestalt" of responsible leadership requires a holistic, integrated "roles model".

\section{The leader as steward}

Navigating in a global world of complexity, uncertainty, change and conflicting interests and values is a challenging endeavour, especially when business is done across borders of countries and cultures. It requires from leaders a global perspective on the business challenges (Black et al., 1999), a social and moral radar to assess the social, ecological and cultural environment and the ability to cope with conflicting stakeholder expectations and ethical dilemmas (De George, 1993; Donaldson, 1996). Against this background, the metaphor of the leader as steward makes reference to being a guardian of values, a stronghold to protect personal and professional integrity, and steering a business responsibly and respectfully, even through troubled (global) waters, thus protecting and preserving what one is entrusted with. Block (1993) notes that a steward used to be someone who was entrusted with leading a kingdom, while the king or those rightfully in charge were away or still underage. Stewardship is to hold something in trust. If we connect this idea to the values and resources at stake, then we suggest to think of a responsible leader as someone who understands herself as a custodian of social, moral and environmental values and resources. Leaders should protect and, whenever possible, enrich what they are entrusted with, business and otherwise. The core question they have to ask themselves is: "What am I passing on to the next (and future) generations?" (Maak and Pless, 2006: 46). A steward considers the potential claims and future interests of hitherto voiceless stakeholders - the environment and future generations. Thus, not surprisingly, the stewardship ethos provides the normative foundation for addressing issues and challenges of sustainability (Hart, 2005). It is this normative base that helps leaders cope with ambiguities and navigate through an uncertain, multicultural and diverse world. A strong normative values base is on the one hand an important anchor that helps leaders in times of change, e.g. as to assess how much and what kind of change is necessary. On the other hand it is an important compass that helps them in dealing with conflicting stakeholder values, demands and interests and guides them in assessing when different is different and needs to be respected and when different is wrong (Donaldson, 1996).

\section{The leader as citizen}

How can leaders reconcile the idea of an efficiencydriven organization with the idea of thriving communities and a good society? The answer is by being an active and reflective citizen and by promoting active citizenship both within and outside the organization. A reflective citizenship ethos helps leading a business in a stakeholder society by overcoming the problematic separation of "private" business world on the one hand and "public" sphere on the other. The leader as citizen recognizes that both are inevitably connected to each other. A thriving community needs flourishing businesses and business can only flourish, at least in the long run, if it can build on a healthy community and customer base. Thus, leaders as citizen are as concerned about civic health (Schudson, 1998) as they are about business matters; they are committed to the common good and will engage in activities to further the wellbeing of the political community. Moreover, the notion of citizenship implies for every profession an explicit sense of professionalism (Donaldson, 2000; Sullivan, 2004). Business leaders are more than "people with good tools" (Donaldson, 2000: 90), who fulfil their duties to a restricted group of financial stakeholders (shareholders, etc.). Instead, like other professions, leaders have under their care different stakeholders and the human community at large. A hallmark of professionalism is the ability to balance the various responsibilities, to integrate business and civil duties. Business leaders need to understand themselves as integrated members of the community, although they cannot entirely be absorbed by it. Citizens value political, economical and intellectual freedom as well as their free space, moral (Donaldson and Dunfee, 1999) and otherwise. Both, however, are conditional, secured by, and cultivated in, a healthy community in which civic virtues like mutual respect and recognition, tolerance, fairness and inclusion are valued. (Dagger, 1997) Such civility (Barber, 1999), based on 
republican liberalism (Dagger, 1997; Ulrich, 1997) or liberal republicanism (Maak, 1999), is not only morally desirable; it also serves a leader particularly well in being and staying connected to multiple stakeholders. The leader, too, is a member of civil society and thus looks at stakeholders not as "aliens" but as equally integrated members of the (political) community. In fact, being at ease with the characteristics of civility - commonality, deliberation, inclusiveness, listening, learning and development (Barber, 1999: 42-43) - is equally important and helpful for stakeholder engagement and dialogue.

\section{The leader as visionary}

Envisioning a desired future is an important part of responsible leadership. Having a vision that appeals to followers, or which was developed with followers as stakeholders, gives people and organizations direction. In a stakeholder society a responsible vision would ideally build on an ethically sound notion of balanced values creation that leads to sustainable business; ensuring both economic success and the well-being of nature and society. In general, most definitions imply "that vision may be conceived of a set of beliefs about how people should act, and interact, to attain some idealized future state" (Strange and Mumford, 2002: 344). In leadership research this usually comes down to a solitary action by the leader; it is the leader who wants the organization (and its people) to achieve a specific, idealized goal (Conger, 1999). Therefore, not surprisingly, the idea of the leader as visionary is predominantly connected to the notion of charismatic and/or ideological leadership (Conger, 1999; Strange and Mumford, 2002, 2005). The problem with charismatic leadership is, however, that it raises many, if not more questions about ethics, since it can be the best and the worst kinds of leadership, depending on whether you look at a Ghandi or a Hitler (Ciulla, 2004). Solomon (1998: 95), therefore, notes: "Charisma (...) is a generalized way of pointing to and emptily explaining an emotional relationship that is too readily characterised as fascination." Since as a concept it has no ethical value, Solomon argues, we should rather focus on trust: it is neither important, nor desirable that followers are emotionally attracted to leaders (by way of cha- risma); it is, however, important that they can trust a leader on the merits of her values, actions and integrity. More so, it is very likely that while employees or shareholders may think of a CEO as charismatic, his style and performance may offend other stakeholders. Being charismatic in a certain context "does not mean that you are ethical when judged against moral concepts that apply in larger contexts" (Ciulla, 2004: 320). While the inner context of the organization may be receptive to a leader's charisma the outer context may not be at all (Pettigrew, 1987). Thus, from an ethical perspective and in the context of a stakeholder society, charismatic leadership is highly problematic. But does this affect the notion of the leader as visionary? Only if having a vision would be inextricable from being charismatic. While most studies attribute vision as key element to charismatic leadership (Conger, 1999) we find no evidence that vision presupposes charisma. We can, therefore, contend that - beyond charisma - developing and having a vision of a desired future and ways and means to get there is an important element of responsible leadership. Equally, beyond solitary confinement, this requires leaders to engage stakeholders in the process of generating a vision as they are, and will be, affected by it. The individual leader may be responsible for facilitating the process of envisioning (rather than "selling" a pre-defined vision), thereby linking people and issues, setting impulses and enabling co-creation for a common and good vision.

\section{The leader as servant}

Among the few existing explicitly normative concepts of leadership, the idea of servant leadership has arguably been the most influential, aside from Burns' concept of transforming leadership (1978). Greenleaf (1977/2002), a former AT\&T executive, developed the basic concept of servant leadership after reading Hesse's novel "The Journey to the East", where the servant Leo turns out to be the true leader of a group of travellers on a spiritual journey. What makes the idea of the leader as servant so appealing for many scholars (Spears, 1998; Spears and Lawrence, 2004; Hunter, 2004), but particularly also practitioners, is the striking idea that leadership is not about the grandiosity of a leader but about those he or she 
serves. If serving others is the core of leadership then this has profound implications for both the dynamics and the responsibilities of leadership. Serving others requires on the one hand attentiveness, humility and modesty; on the other hand, it requires a willingness and desire to support others and to care for their interests and needs. We find strong elements of both, an ethics of recognition (Honneth, 1996; Maak, 1999) and an "ethics of care" (Gilligan, 1982; Held, 2005; Noddings, 1984/2003; Tronto, 1993) in servant leadership. Gilligan understands caring as an interdependent principle, which remains psychological in its concern with relationships and becomes universal in its condemnation of exploitation and hurt. Here we find the link to an ethics of recognition, which implies for servant leaders to recognize and respect others as vulnerable and equal human beings (Pless and Maak, 2004). An ethics of care also implies an increasing differentiation of self and other, and a growing comprehension of the dynamics of social interaction. In fact, the servant leader needs a high degree of RI to relate to different stakeholders, to cope with the interactive dynamics and to mobilize people to work together for a common purpose. In fact, he needs to be aware of and able to control his own emotions, feelings, values and interests and needs to be able to recognize them in followers in order to act and connect emotionally intelligent with them. Serving others within the organization and caring for their well-being implies for instance to support life-work balance; to ensure a safe, healthy and respectful work environment, meaningful work, fair pay, equal and fair employment and career opportunities regardless of gender, nationality, religion etc.; to help followers deal with the struggles of change and to nurture development and growth of people, thereby encouraging the "release of human possibilities" (Gardner, 1990: 74). The latter already refers to the role of the leader as coach.

Finally, the idea of the leader as servant is not limited to employees or internal stakeholders. With it comes a strong sense of community and thereby a much broader focus on other stakeholders (including the environment and future generations). A servant leader pursues a vision and respective goals that are compatible with the needs and interests of all relevant stakeholders and that are shared by followers. Being good at building relationships towards these stakeholders, the servant leader initiates and engages in stakeholder dialogue; has a deep interest in and is well informed about the social and environmental context he and his corporation are operating in; tries to understand, respect and recognize stakeholder needs; integrates multiple perspectives into a balanced and morally sound decision-making approach. As listener and facilitator the servant leader prefers a thriving community to individual stardom. In fact, the true merits of a leader's service may not always be obvious. But things may fall apart if a community of stakeholders does not receive it, as Hesse reminds us: "It was the absence of the servant Leo which revealed to us, suddenly and terribly, the extent of the dissention and the perplexities which shattered our hitherto apparent complex unity. (...) Hardly had Leo left us, when faith and concord amongst us was at an end; it was as if the life-blood of our group flowed away from an invisible wound." (1956: 112113)

\section{The leader as coach}

In times of ongoing change, in organizations as well as in markets, the role of the leader as coach cannot be underestimated. In fact, it is a key role in relation to immediate followers. Here, relationship skills come to life, as do care and recognition. In general, it involves facilitating development, enabling learning, and supporting individuals and teams in achieving their objectives. Of particular importance are: integrating and motivating people from multiple backgrounds to work together to realize a common vision. The leader as coach, thereby, supports the relational process and fosters collaborative interaction, open communication and constructive conflict solution (Kets de Vries and Florent-Treacy, 1999) and ensures that the interactive processes are fair and inclusive, so that people from different backgrounds feel recognized and respected and encouraged to contribute to their highest potential. In order to do that leaders need to be aware of and able to control their own and others' emotions (Wills and Barham, 1994); to understand and cope with cultural differences, show respectful behaviour, apply cross-cultural empathy (Kets de Vries and Florent-Treacy, 1999) and be able to give (and receive) feedback in a cross-culturally appropriate and timely manner to 
foster desired interpersonal and moral behaviour in followers. In a multicultural stakeholder environment, with diverse values and multiple interests, leaders also need to provide support to followers who face conflicts of interests and moral areas of ambiguity (Donaldson, 1996; Donaldson and Dunfee, 1999), for instance by providing on-going training to develop relational and ethical competencies and by acting as a discussion partner when ethical issues and dilemmas occur. This requires ethically intelligent leaders who act as role models, based on moral values, show that ethics and integrity matter (Trevino et al., 1998; Weaver et al., 1999), apply strong reflection skills and use advanced moral reasoning (Dalton, 1998), as well as moral imagination. Leaders provide coaching to their followers to help them develop relational qualities that help them balance conflicting emotions, feeling, values, needs and interests in themselves and with their interaction partners.

\section{The leader as architect}

The metaphor of leader as architect refers to the challenge of building an inclusive integrity culture (Pless and Maak, 2004). Leaders need to create and cultivate a work environment where diverse people find meaning, feel respected, recognized and included (thus, not discriminated or harassed); where they have fun and feel mobilized and thus enabled to contribute to their highest potential, both in a business and a moral sense. The leader as architect also makes sure that management systems and processes are designed in a way that support the effective and ethical achievement and monitoring of the triple-bottom-line and the realization of the shared vision. For instance, they implement and actively support a moral infrastructure (policies, guidelines, business principles and audits) and assure that HR management systems (e.g. recruitment, promotion) are based on moral values such as respect, honesty, tolerance, fairness etc. (Pless and Maak, 2004). They also insure that these systems are integrated and aligned to the shared vision and the common objectives (business, social and ecological). That means for instance that HR performance management systems are integrated and measure and reward desired behaviour (e.g. co-operation and integration of people from different cultures into a discussion; application of advanced moral reasoning; mature mediation of stakeholder conflicts; reconciliation of ethical dilemmas). With respect to external stakeholders they institutionalize and nurture an on-going dialogue with all relevant stakeholders as a basis for sustaining mutually beneficial and trustful stakeholder relationships.

\section{The leader as storyteller and meaning enabler}

Drawing on the work of Smircich and Morgan (1982), we can look at leaders as creators of shared systems of meaning, through sensemaking and dialogue; e.g. leading both internal and external stakeholders in sustainable partnerships to an integrative view of business success and the common good. A very useful tool to support the creation of meaning and sensemaking is the use of stories. (Armstrong, 1999; Boje, 1991) As creator and communicator of moral experience and shared systems of meaning a leader has the task to breathe life into both individual and organizational responsibility. Giving out cards that state a company's core values may be useful to remind people what these values are. More importantly, however, is for people to know what is at stake, e.g. with respect to human rights. Thus, to symbolize the significance of human rights by way of a story can be an important means to bring their protection to life. "The Body Shop" founder Roddick used storytelling widely to spread her mission and communicate her vision of a socially, culturally and environmentally friendly business that can make a difference in the world through ongoing commitment, fair trade and active citizenship behaviour: "I believe that one of the most effective means of communication is storytelling. (...), stories about products and stories about the organization. Stories about how and where we find ingredients bring meaning to our essentially meaningless products, while stories about the company bind and preserve our history and our sense of common purpose" (2000: 79-80). Stories illustrate and transport core values and they trigger our moral imagination. Stories are an important element in the search for meaning and help in sensemaking (Weick, 1995) vis-à-vis the notion of individual and collective responsibility. 
The leader as change agent

Finally, drawing on the discussion on transformational leadership we understand leaders also as change agents, who are responsible to initiate and/or support change towards a value-conscious and sustainable business in a stakeholder society. While we can discuss here neither the pros and cons of Burns' concept of "transforming leadership" (1978), nor Bass and Steidlmeier's (1999) take on "transformational leadership", we would like to stress the idea of responsible change. Business leaders have to deal with the fact of constant change; hence, it seems important to note that first, initiating change is not an end in itself and second that it needs to be conducted and facilitated in a caring and responsible manner. As a change agent, the leader is responsible for mobilizing stakeholders, building and sustaining commitment among followers through ongoing sensemaking activities, reducing complexity and anxiety, and ultimately, keeping momentum in times when change causes insecurity and disorientation. The task and challenges can best be met by creating a "holding environment" (Kets de Vries and FlorentTreacy, 1999: xvii) and by upholding a clear vision and purpose.

\section{Conclusion}

The goal of the present paper was to discuss the concept of responsible leadership in the context of stakeholder theory. We argued that leadership is a social-relational and ethical phenomenon that occurs in interaction between a leader and a broader group of followers, inside and outside the organization. These followers are in fact a leader's stakeholders they are either affected by a leader's action or have a stake in the leadership project. Often, they have an equal status. In this article, we therefore contended that in a global and networked stakeholder environment the concept of the leader as the great man at the top of the pyramid, as the main creator of economic and social reality with followers as subordinates who are dedicated to "do the leader's wishes", is no longer valid. Instead, leaders are understood as equal human beings who earn a license to lead from their followers. They are weavers who bring together different people to follow a shared and morally sound vision. They are facilitators of relational processes of co-creation and orchestrators for achieving common objectives. Furthermore, we argued that they need moral character and relational qualities to build sustainable relationships and cope with the complex leadership challenges in a global, uncertain and interconnected environment. Finally, we introduced the roles model of responsible leadership, which gives a gestalt to a responsible leader and describes the different roles he or she takes in leading stakeholders and business in society.

However, introducing the roles model of responsible leadership is only a first step. To better understand the phenomenon of responsible leadership further research is necessary to shed light on the relationship between the roles. While we do not suggest that the roles are independent from each other, it is important to study how and to what degree the different roles are interdependent. In fact, some roles create a dialectical tension, for instance, the steward as the preserver of values and the change agent as the transformer of the status quo. Therefore, it is fruitful to examine how a responsible leader perceives, approaches and resolves these dialectical tensions. Further insights into the interplay between the roles are necessary to substantiate the roles model.

Important to future research is also an attempt to understand the interaction between character and RI on the individual level and to study how the intrapersonal processes translate into responsible leadership behaviour and the discussed roles. In this regard it can be helpful to conduct biographical and psychoanalytical studies of responsible leaders to gather further insights into the connection between values, experiences and the performance of responsible leadership roles and behaviour. In addition, from a practical HR perspective it is productive to further specify the roles of responsible leadership by defining competencies and observable behaviours for each of these roles. It is also critical to examine how the leadership context influences the performance of responsible leadership behaviour. Finally, we would like to stress that it is important to study the relationship with followers and how they influence responsible leadership behaviour. We hope that this paper has opened up new vistas on responsible leadership and paved the way for future research in this direction. 


\section{References}

Armstrong, D. M.: 1999, Managing by Storying Around (Armstrong Intl, Three Rivers, MI).

Badaracco, J. L., Jr: 2001, 'We Don't Need Another Hero', Harvard Business Review 79(8), 121-126.

Barber, B. R.: 1999, 'The Discourse of Civility', in S. L. Elkin and K. E. Soltan (eds), Citizen Competence and Democratic Institutions (Penn State University Press, University Park, PA), pp. 39-47.

Bass, B. M.: 1967, 'Some Effects on a Group of Whether and When the Head Reveals His Opinion', Organizational Behavior and Human Performance 2, 375-382.

Bass, B. M.: 1990, Bass \& Stogdill's Handbook of Leadership 3rd edition, (The Free Press, New York).

Bass, B. M. and P. Steidlmeier: 1999, 'Ethics, Character, and Authentic Transformational Leadership Behavior', Leadership Quarterly 10, 181-217.

Bennis, W. and B. Nanus: 1985, Leaders: The Strategies for Taking Charge (Harper \& Row, New York).

Berger, P. L. and T. Luckmann: 1966, The Social Construction of Reality (Doubleday, Garden City, NY).

Black, J. S., A. J. Morrison and H. B. Gregersen: 1999, Global Explorers: The Next Generation of Leaders (Routledge, New York/London).

Blake, R. R. and J. S. Mouton: 1985, The Managerial Grid III (Gulf, Houston, TX).

Block, P.: 1993, Stewardship Choosing Service over SelfInterest (Berrett-Koehler, San Francsico).

Boje, D. M.: 1991, 'The Storytelling Organization: A Study of Performance in an Office-Supply Firm', Administrative Science Quarterly 36, 106-126.

Brundtland, G. H.: 1987, Our Common Future: The World Commission on Environment and Development (University Press, Oxford).

Burns, J. M.: 1978, Leadership (Perennial, New York)

Ciulla, J.: 1995, 'Leadership Ethics: Mapping the Territory', Business Ethics Quarterly 5(1), 5-28.

Ciulla, J.: 1998, Ethics, The Heart of Leadership (Praeger, Westport, CT, London).

Ciulla, J.: 2004, 'Ethics and Leadership Effectiveness', in J. Antonakis, A. T. Cianciolo and R. J. Sternberg (eds), The Nature of Leadership (Sage, Thousand Oaks/ London/New Dehli), pp. 302-327.

Ciulla, J.: 2006, 'Ethics. The Heart of Leadership', in Th. Maak and N. M. Pless (eds), Responsible Leadership (Routledge, London/New York).

Cole, M., Bruch, H. and Vogel, B. (2005) Development and Validation of a Measure of Organizational Energy. in: K. M.Weaver (ed.) Proceedings of the Sixty-fifth Annual Meeting of the Academy of Management (Honolulu, HI).
Collins, J.: 2001, Good to Great (HarperCollins, New York).

Conger, J. A.: 1999, 'Charismatic and Transformational Leadership in Organizations: An Insider's Perspective on these Developing Streams of Research', The Leadership Quarterly 10(2), 145-179.

Conger, J. A. and R. N. Kanungo: 1987, 'Towards a Behavioral Theory of Charismatic Leadership in Organizational Setting', Academy of Management Review 12, 637-647.

Cox, T., Jr: 2001, Creating the Multicultural Organization (Jossey-Bass, San Francisco).

Dachler, H. P.: 1992, 'Management and Leadership as Relational Phenomena', in M. v. Cranach, W. Doise and G. Mugny (eds), Social Representations and the Social Base of Knowledge (Hogrefe \& Huber Publishers, Lewiston, NY/Toronto/Bern/Göttingen).

Dagger, R.: 1997, Civic Virtues: Rights, Citizenship, and Republican Liberalism (Oxford University Press, New York/Oxford).

Dalton, M. A.: 1998, 'Developing Leaders for Global Roles', in C. D. McCauley, R. S. Moxley and E. VelsorVan (eds), The Center for Creative Leadership Handbook of Leadership Development (Jossey-Bass, San Francisco), pp. 379-402.

De George, R. T.: 1993, Competing with Integrity in International Business (Oxford University Press, Oxford/New York).

DiPiazza, S. A., Jr and R. G. Eccles: 2002, Building Public Trust: The Future of Corporate Reporting (John Wiley \& Sons, New York).

Donaldson, T.: 1996, 'Values in Tension: Ethics Away from Home', Harvard Business Review 74(5), $48-56$.

Donaldson, T.: 2000, 'Are Business Managers "Professionals"?’, Business Ethics Quarterly 10(1), 83-94.

Donaldson, T. and T. Dunfee: 1999, Ties that Bind (Harvard Business School Press, Boston).

Donaldson, T. and L. E. Preston: 1995, 'The Stakeholder Theory of the Corporation: Concepts, Evidence, and Implications', Academy of Management Review 20(1), 65-91.

Elkington, J.: 1998, Cannibals with Forks: The Triple Bottom Line of 21st Century Business (New Society Publishers, Gabriola Island, BC/Stony Creek, CT).

Fiedler, F. E.: 1967, A Theory of Leadership Effectiveness (McGraw-Hill, New York).

Freeman, R. E.: 1984, Strategic Management: A Stakeholder Approach (Pitman Publishers, Boston).

Freeman, R. E.: 2004, 'Ethical Leadership and Creating Value for Stakeholders', in R. A. Peterson and O. C. Ferrell (eds), Business Ethics (M.E. Sharpe, Armonk, NY, London). 
Freeman, R. E.: 2005, 'The Stakeholder Approach Revisited', Zeitschrift für Wirtschafts- und Unternehmensethik 5(3), 228-241.

Freeman, R. E. and D. R. Gilbert: 1989, Corporate Strategy and the Search for Ethics (Prentice-Hall, Englewood Cliffs, NJ).

Freeman, R. E., Martin, K., Parmar, B., Cording, M. P. and Werhane, P. H. 2006, 'Leading through Values and Ethical Principles', in R. Burke and C. Cooper (eds), Inspiring Leaders (Routledge, London, New York) (in press).

Freeman, R. E., A. C. Wicks and B. Parmar: 2004, 'Stakeholder Theory and 'the Corporate Objective Revisited”, Organization Science 15(3), 364-369.

Foster, W. F.: 1989, 'Toward a Critical Practice of Leadership', in J. Smyth (ed.), Critical Perspectives on Educational Leadership (Falmer, London), pp. 39-62.

Gardner, J.: 1990, On Leadership (Free Press, New York)

George, B.: 2003, Authentic Leadership: Rediscovering the Secrets to Creating Lasting Value (Jossey-Bass, San Francisco, CA).

Gilbert, J. A. and J. M. Ivancevich: 2000, 'Valuing Diversity: A Tale of Two Organizations', Academy of Management Executive 14(1), 93-105.

Gilligan, C.: 1982, In a Different Voice (Harvard University Press, Cambridge, MA).

Graen, G. B. and M. Uhl-Bien: 1995, 'Relationshipbased Approach to Leadership: Development of Leader-Member Exchange (LMX) Theory of Leadership over 25 Years: Applying a Multi-Level Multi-Domain Perspective', Leadership Quarterly 6, 219-247.

Greenfield, T. B.: 1984, 'Leaders and Schools: Wilfullness and Nonnatural Order in Organizations', in T. F. Sergiovanni and J. E. Corbally (eds), Leadership and Organizational Culture (University of Illinois Press, Urbana, IL), pp. 142-169.

Greenleaf, R. K.: 1977/2002, Servant Leadership A Journey into the Nature of Legitimate Power \& Greatness, 25th Anniversary ed (Paulist Press, New York/Mahwah, NJ).

Hart, S. L.: 2005, Capitalism at the Crossroads (Wharton School Publishing, Upper Saddle River, NJ).

Held, V.: 2005, Ethics of Care (Oxford University Press, New York/London).

Helgesen, S.: 1990, The Female Advantage: Women's Ways of Leadership (Doubleday, New York).

Hersey, P. and K. Blanchard: 1988, Management of Organizational Behavior: Utilizing Human Resources 5th edition, (Prentice-Hall, Englewood Cliffs, NJ).

Hesse, H.: 1956, The Journey to the East (Picador, New York).

Honneth, A.: 1996, The Struggle for Recognition: The Moral Grammar of Social Conflicts (MIT Press, Cambridge, MA).
Howell, J. M. and B. J. Aviolo: 1992, 'The Ethics of Charismatic Leadership: Submission or Liberation', Academy of Management Executive 6(2), 4354.

Hunter, J. C.: 2004, The World's Most Powerful Leadership Principle: How to Become a Servant Leader (Crown Business, New York).

Johnson, M.: 1993, Moral Imagination: Implications of Cognitive Science for Ethics (The University of Chicago Press, Chicago/London).

Kellerman, B.: 2004, Bad Leadership: What it is, How it Happens, Why it Matters (Harvard Business School Press, Boston, MA).

Kets de Vries, M. F. R. and E. Florent-Treacy: 1999, The New Global Leaders (Jossey-Bass, San Francisco).

Maak, Th.: 1999, Die Wirtschaft der Bürgergesellschaft (Haupt, Bern/Stuttgart/Vienna).

Maak, Th. and N. M. Pless: 2006, 'Responsible Leadership: A Relational Approach', in Th. Maak and N. M. Pless (eds), Responsible Leadership (Routledge, London, New York).

Maccoby, M.: 2000, 'Narcissistic Leaders: The Increadible Pros, The Increadible Cons', Harvard Business Review 78(1), 69-77.

Mayer, J. D., P. Salovey, D. R. Caruso and G. Sitarenios: 2001, 'Emotional Intelligence as a Standard Intelligence', Emotion 1, 232-242.

Merton, R. K.: 1957, 'The Role-Set: Problems in Sociological Theory', The British Journal of Sociology 8(2), 106-120.

Mintzberg, H.: 1975, 'The Manager's Job: Folklore and Fact', Harvard Business Review July-August, 49-61.

Nicoll, D.: 1986, 'Leadership and Followership: Fresh Views on an Old Subject', in J. A. Adams (eds), Transforming Leadership (Miles River Press, Alexandria, VA), pp. 29-38.

Noddings, N.: 1984/2003, Caring: A Feminine Approach to Ethics and Moral Education (University of California Press, Berkeley).

Pettigrew, A. M.: 1987, 'Context and Action in the Transformation of the Firm', Journal of Management Studies 24, 649-670.

Phillips, R.: 2003, Stakeholder Theory and Organizational Ethics (Berrett-Koehler, San Francisco).

Pless, N. M. and Th. Maak: 2004, 'Building an Inclusive Diversity Culture: Principles, Processes and Practice', Journal of Business Ethics 54, 129-147.

Pless, N.M. and Maak, Th. 2005, 'Relational Intelligence for Leading Responsibly in a Connected World', in K. M. Weaver (ed.), Proceedings of the Sixty-fifth Annual Meeting of the Academy of Management (Honolulu, HI). 
Pless, N. M. and R. Schneider: 2006, 'Towards Developing Responsible Global Leaders: The Ulysses Experience', in Th. Maak and N. M. Pless (eds), Responsible Leadership (Routledge, London, New York).

Roddick, A.: 1991, Body and Soul: Profits with Principles (Crown Publishers, New York).

Roddick, A.: 2000, Business as Unusual (Thorsons, London).

Rooke, D. and W. Torbert: 2005, '7 Transformations of Leadership', Harvard Business Review 83, 67-76.

Rost, J. C.: 1991, Leadership for the 21st Century (Quorum, Westport, CT/London).

Salovey, P. and J. D. Mayer: 1990, 'Emotional Intelligence', Imagination, Cognition and Personality 9(3), 185-211.

Schön, D. A.: 1983, The Reflective Practitioner: How Professionals Think in Action (Basic Books, New York).

Schudson, M.: 1998, The Good Citizen (The Free Press, New York).

Smircich, L. and G. Morgan: 1982, 'Leadership: The Management of Meaning', Journal of Applied Behavioral Science 18, 257-273.

Solomon, R. C.: 1998, 'Ethical Leadership, Emotions, and Trust: Beyond "Charisma", in J. Ciulla (ed.), Ethics, the Heart of Leadership (Praeger, Westport, CT/ London), pp. 87-107.

Solomon, R. C.: 1999, A Better Way to Think about Business (Oxford University Press, New York, Oxford).

Spears, L. C.: 1998, Insights on Leadership: Service, Stewardship, Spirit, and Servant leadership (John Wiley \& Sons, New York etc.).

Spears, L. C. and M. Lawrence: 2004, Practicing Servant Leadership (Jossey-Bass, San Francisco).

Strange, J. M. and M. D. Mumford: 2002, 'The Origins of Vision: Charismatic Versus Ideological Leadership', Leadership Quarterly 13, 343-377.

Strange, J. M. and M. D. Mumford: 2005, 'The Origins of Vision: Effects of Reflection, Models, and Analysis', Leadership Quarterly 16, 121-148.

Sullivan, W. M.: 2004, Work and Integrity: The Crisis and Promise of Professionalism in America (Jossey-Bass, San Francisco).

Svendsen, A.: 1998, The Stakeholder Strategy (BerrettKoehler, San Francisco).

The Body Shop: 2004, What is community trade? Online. Available http://www.thebodyshopinterna- tional.com/web/tbsgl/values_sct_what.jsp (accessed Nov. 1, 2004).

Trevino, L. K., K. B. Butterfield and D. L. McCabe: 1998, 'The Ethical Context in Organizations: Influences on Employee Attitudes and Behaviours', Business Ethics Quarterly 8(3), 447-476.

Tronto, J. C.: 1993, Moral Boundaries A Political Argument for an Ethic of Care (Routledge, New York/London).

Ulrich, P.: 1997, Integrative Wirtschaftsethik (Haupt, Bern/ Stuttgart/Wien).

Wade, M.: 2006, 'Developing Leaders for Sustainable Business', in Th. Maak and N. M. Pless (eds), Responsible Leadership (Routledge, London, New York), pp. 227-244.

Weaver, G., L. K. Trevino and P. Cochran: 1999, 'Corporate Ethics Programs as Control Systems: Influences of Executive Commitment and Environmental Factors', Academy of Management Journal 42(1), 41-57.

Weick, K. E.: 1995, Sensemaking in Organizations (Sage, Thousand Oaks, CA).

Werhane, P.: 1999, Moral Imagination and Management Decision Making (Oxford University Press, New York/ Oxford).

Wheeler, S. and M. Sillanpää: 1997, The Stakeholder Corporation (Pitman Publishing, London etc.).

Wicks, A. C., D. R. Gilbert, Jr and R. E. Freeman: 1994, 'A Feminist Reinterpretation of the Stakeholder Concept', Business Ethics Quarterly 4(4), 475-497.

Wills, S. and K. Barham: 1994, 'Being an International Manager', European Management Journal 12(1), 49-58.

Thomas Maak

Institute for Business Ethics

University of St. Gallen

Guisanstrasse 11, CH-9010

St. Gallen, Switzerland

E-mail: thomas.maak@unisg.ch

Nicola M. Pless

INSEAD PwC-Initiative on

high-performing organizations

Boulevard de Constance

77305, Fontainebleau Cedex

France 